\title{
Research on National Security Cognition Level of College Students in the New Era
}

\author{
Fan Jiangyan*, Zhang Hongbing \\ Basic Department, Engineering University of PAP, Xi'an, China \\ Email address: \\ 654396497@qq.com (Fan Jiangyan), 100272347@qq.com (Zhang Hongbing) \\ ${ }^{*}$ Corresponding author
}

\section{To cite this article:}

Fan Jiangyan, Zhang Hongbing. Research on National Security Cognition Level of College Students in the New Era. Humanities and Social Sciences. Vol. 8, No. 1, 2020, pp. 25-29. doi: 10.11648/j.hss.20200801.14

Received: December 3, 2019; Accepted: February 13, 2020; Published: February 25, 2020

\begin{abstract}
At present, the holistic view of national security education has the characteristics of marginalization, fragmentation of content and formalization of implementation. The situation of security education is not optimistic. In order to cope with the risks and challenges of foreign hostile forces penetrating into the ideological field of our country better, ensure the security and stability of our country in the critical and tackling period, it has become an urgent issue of the times to focus on the development level, existing problems and cultivation path of the holistic view of national security of the young people in the new era. However, at present, the research on the youth's holistic view of national security based only on the dimension of "country", "construction" and "cognition" is somewhat monotonous, and there are few studies on the measurement system from the macro (country) to the micro (cognition) level. Scholars conducted empirical research on the cognition and identity of college students from different perspectives of national security, and use basic statistical tools to analyze the internalization status of college students' holistic view of national security. All of them show that college students' security awareness is weak. But specifically, which level of cognition has the problem, what are the influencing factors, there is no systematic and comprehensive answer. The fusion analysis based on national security, psychology and statistics will give a better answer to this problem.
\end{abstract}

Keywords: National Security, Holistic View of National Security, Development Level, Cognitive Measurement, Statistical Analysis, Cross Fusion

\section{Research from the Perspective of National Security Theory}

American psychologist Maslow proposed the hierarchy of needs theory in 1943, considering safety as the first need of a person after meeting physiological needs, and pointed out that the entire organism is a mechanism to pursue safety.

When did the concept of "national security" emerge? Based on the research of the British scholar Peter Mangold, the term "national security" was first used in the American newspaper columnist Lippman's 1943 book "American Foreign Policy". Whether a country is safe or not is the primary concern of every sovereign country. Its constituent elements are also constantly adjusted and developed with the evolution of history and changes in the international and domestic situation. Liu Xuelin pointed out that Japan's recognition of "threat" and its value judgment after the Cold War drove the formation of its new national security concept, and that the collective identity of the people played a significant role [1]. Li Jiaheng summarized the evolution of the components of China 's national security, from "military security, homeland security and political security" in the Mao Zedong era, through the evolution of the Deng Xiaoping era, the Jiang Zemin era and the Hu Jintao era to the Xi Jinping era, national security has evolved to eleven elements of the structural system [2]. Xiao Ke used constructivist theory to analyze national security, and proposed a new perspective of security concept-from the state-oriented to the human-centered [3]. With the help of Citespace, $\mathrm{Xu}$ Dongbo explored the evolution of national security research hotspots in the past ten years. From only focus on traditional security research at the beginning to mid-term traditional security and non-traditional security. Until 2014, President Xi first proposed an overall national 
security concept and national security research, major changes began to occur [4]. In recent years, the theoretical research on the overall national security concept has yielded fruitful results. Hu Hongbin summarizes the history of China 's national security research into three transitions based on three perspectives: national security awareness research, national security theory paradigm research and national security challenge research. The first is '"traditional dualism' to 'non-traditional infinity.' Transformation "; the second is" the transformation of Marxism's "monopoly dominance" to 'pluralism'; The third is "the transformation of 'ideological conflicts' to 'multiple internal and external drivers"' [5].

Under the "national" dimension, scholars have clarified the relationship between "state-security" from the perspectives of international politics, national security, and international strategy, and clarified that the "national security" perception is "national" Internal performance and external expansion. Tian Qiubao expounded the issue of national cognition in the international anarchy [6]. Han Zhiming and others extended the national image to the national honor [7]. Shi Haiming and Zeng Huafeng proposed the "National Cognitive Space Security Strategy from the Perspective of Science and Technology and War" and studied the relationship between national cognition and the overall national security concept from the perspective of national strategy [8].

Under the "construction" dimension, historical research methods, comparative research methods and institutional research methods are used to describe the spiral interaction between "state-security" in a broad perspective. Starting from the party congresses of the Communist Party of China, Liu Peng studied the Communist Party 's basic understanding of China and its future vision, and combined with major political and economic changes at home and abroad to analyze the changes in the field of communication and public opinion caused by changes in the cognitive field [9]. Liu Danling explained the interaction between the national image and the perception of the overall national security concept by constructing a model of "imaged" national image [10]. Liu Zhongquan analyzed Deng Xiaoping's national epistemology [11]. Qu Jun studied the national cognition of literati in the era of transition (1895-1925) in Chinese history [12]. Foreign scholars conduct more research from the theory of national identity and rarely discuss the cultivation of the "process" of cognition generation, while domestic scholars' "process" research is partial to public culture, dogmatic, and qualitative, and needs to be supported by practical quantitative survey data.

\section{Research from the Psychological Perspective}

The entire psychological process of internalization of the overall national security view of college students has gone through four stages of "graphical cognition, passive compliance, local assimilation and conformity". "Graphic cognition" is the initial stage of internalization and the most basic stage. In this period, under the interpretation and interpretation, propaganda and education of educators, college students understood and understood the overall national security concept and formed a preliminary cognitive attitude [13].

Cognition refers to the process by which people acquire knowledge or apply knowledge, or the process of information processing. Wang Dan defined the safety awareness of coal miners as a response of the brain to objectively unsafe factors, such as the identification of dangerous sources when working downhole [14]. From Erikson to Piaget and Weil, after the scholars such as Barrett and Jahoda in the 1990s, the theory of youth cognitive development is more mature, and it is clear that cognition is the youth's views, perceptions, memory and imagination on specific content, nature, meaning, structure and etc. The U.S. military has proposed the categories of "physical domain", "information domain" and "cognitive domain". These constitute three major spaces side by side. Based on this division, we have discussed the current national security situation and pointed out that national security has not only Built only on the physical domain, it began to spread to the cognitive domain and became a new area of national security. This field more reflects the emotional will, knowledge and belief of people [15]. Zeng Huafeng and Shi Haiming summarized strategic space into "natural space", "technical space", "social space", and "cognitive space" [16]. But no matter how scholars divide the concept of space, they are beginning to connect national security with cognitive domains.

The particularity of cognitive space makes national security face greater risks and challenges. First, the cognitive domain does not have a clear security boundary. It exists in people's psychology and thoughts, and is more uncontrollable than cyberspace. Second, it is extremely diffusive. The security threat factors in cognitive space can easily spread to natural space, which has a great impact on our real life. The third is the persistence of strategic confrontation. The struggle in cognitive space is not determined by several battles and fights. It is a long-term subtle infiltration and erosion to manipulate ideas. In the end, it leads us to the abyss that is no longer in sight. Before the collapse of the Soviet Union, the West used "Voice of America", "Radio Free Europe" and "BBC Radio" to conduct all-weather ideological penetration of socialist countries. The famous American political scientist Samuel Huntington once said: "For the stability of a traditional society, the main threat is not from the aggression of foreign troops, but from the invasion of foreign ideas. Faster and deeper. "Therefore, the mechanism of the cognitive domain crisis is a micro-to-macro process, that is, by corrupting individuals, shaking our foundations, and then subverting a country and a regime.

At present, college students suffer from various bad information at home and abroad in terms of political ideology, social morality, and psychological safety. Shen Yajun explored and analyzed the security situation of the Internet cognitive domain, and pointed out that the characteristics of the Internet's multiple subjects, virtual objects, and strong 
adversity pose great threats to political security, social security and individual psychological security in our national security [17]. And in view of the current situation, this threat has already spread to non-traditional fields such as cultural security and information security. From the perspective of psychology, Meng Yi, Wang Sufang and others used the theory of behavioral psychology, propaganda psychology and practical psychology to study the fire safety awareness of college students [18]. Zhang Min, Hao Subing and others established a connection between security awareness and security behavior, and analyzed the information security awareness of college students from a micro-level [19]. Qiu Weiguang and Zhang Yaocan pointed out in "Principles of Ideological and Political Education" that "the system of human security consciousness and behavior is a three-dimensional three-dimensional structure with a tendency of stability, which is composed of three subsystems of psychology, thought, and behavior and their multiple elements. N. Dedobbeleer, F. Beland (1991), etc. believe that individual security includes three dimensions---security awareness, security attitude, and security participation. Tian Zhidun studied the influence mechanism of safety cognitive ability on safe behaviors from the cognitive "five forces (attention, memory, observation, imagination and thinking) [20]. Yangcun researched the path of constructing the inherent safety behavior habits of college students, and examined the theoretical basis and formation rules of safety consciousness from the perspectives of social stability theory, social learning epistemology and behavioral science theory. The combination of the two is inseparable from external education and self-awareness. A person's security behavior is closely related to his level of security knowledge, security awareness, security attitude, and security skills [21]. Neal (2000) established a security behavior model that includes two aspects of security compliance and security participation basing on the job performance theory of Campel. So what kind of relationship is between behavior and consciousness? Song Fenglin gave an answer in "Cognitive Dimensions", thinking that all consciousness is essentially accompanied by the process of behavior regulation, and it can be understood that consciousness is a by-product of behavior regulation. Therefore, scholars often use safety behavior as a survey point when researching safety awareness level.

$\mathrm{Yu}$ Xiaofeng and others pointed out that the lack of any "identity" or conflict may cause new security issues. When he commented on Huntington's "Who We Are", he considered "identity" to be an important variable of security, "For on the one hand it 'defines' the formation of security issues, and on the other hand it is an important basis for maintaining security"[22]. In the West, the concept of "identity" was first proposed by William James and Freud. Xie Guiping believes that "security is an identity construction" in the study of border security governance. He proposed a model of the internal driving force relationship of identity. Among the four main driving force variables of identity, "security" is the key variable. Similarly, "identity" is also the inner core of security [23]. Donald, Young (1996) and others found that under the control of certain variables, there is a significant correlation between safety attitudes and safety behaviors. Li Lerong and Weng Chuzhen conducted a multi-dimensional analysis of college students' national identity, and concluded that national identity is mainly composed of four dimensions: identity, cultural, emotional, and behavioral identity [24]. In summary, there are multiple direct and indirect mechanisms of action between "cognition", "identification" and "safe behavior".

\section{Research from the Perspective of Empirical Analysis}

There are currently two main methods for measuring cognitive ability: field investigations and ergonomic laboratory cognitive ability tests, and some scholars have combined the two. Among them, the common methods of field surveys are usually questionnaires or interviews. The field survey can also be called "self-evaluation" to a certain extent, and it is the subjective reflection of the subject's ontological cognition. Dong Hua, Ning Weining, and Hou Guanhua summarized the existing research based on the classification, measurement methods, and influencing factors of cognitive ability, and summarized the cognitive measurement methods into self-evaluation and operation tests. There is no significant correlation, but both can achieve the purpose of effectively predicting the actual observation results. Both measure only different aspects of capability [25]. Although the operation test has high reliability, the test process is cumbersome and difficult to implement. The implementation of self-evaluation is more flexible. Heiner has also used his method to measure, and in the study by Miller L $\mathrm{S}$ et al., it showed more reliable results than self-evaluation.

When measuring cognitive ability, the accuracy and authenticity of the measurement results are often our primary concern. There are many factors that affect the measurement results. In terms of external factors, Kate E. Jacobs and John Roodenburg explored the impact of the design of the questionnaire on self-reported cognitive ability, and found that the aggregation validity of the SRMCA questionnaire on crystal intelligence and visual spatial thinking performed well [26]. Schmitter-EM, Parsey C, and Cook J studied the test effects of different measurement methods and found that the cognitive "five forces" variable can explain the results of the functional status of the operation test at a significant level, while other methods are not [27]. La Fleur C G and Salthouse $\mathrm{T}$ A pointed out that social support factors also have significant effects on cognitive ability, including contact with relatives and friends, emotional support, and negative interpersonal interactions, which can positively or negatively affect cognitive ability [28]. Holland and others believe that in the social communication network, the object can be regarded as a third party in the network structure. If the two people's attitudes towards the third party differ, there will be discomfort. Therefore, people usually change their attitudes and behaviors and value judgments of third parties to achieve a state of internal cognitive consistency [29]. This explains, to 
some extent, why social support affects people's cognitive ability. Regarding the mechanism of internal factors, Lydia Soh and Kate E. Jacobs found that different personality traits and gender have different effects on self-reported cognitive ability [30]. Personality characteristics not only produce different self-reporting tendencies, but also directly affect individual cognitive ability. Yang Y W and Lim H S explored the impact of different cognitive load on cognitive ability of individuals [31]. Zsembik B A and Peek M K found that even when controlling various social factor variables, there were significant differences in cognitive ability among various races [32]. However, Rodgers W L and Ofstedal MB did not think that cognitive ability had significant intergenerational differences.

Scholars have made fruitful research results on the measurement of cognitive ability. Then what is the current state of cognitive ability of college students, scholars also gave survey results and empirical analysis from different perspectives. Jiang Liping's survey of college students' non-traditional security awareness found that contemporary college students have problems with less contact with non-traditional security threats and vague understanding. The data shows that only $6.79 \%$ of students obtain non-traditional safety-related knowledge through school education, which fully shows that there are still huge problems in national security education in colleges and universities. $28.72 \%$ of students stated that they were greatly influenced by the West through games, movies, books, etc., especially in regard to the attitude of "peaceful evolution", which performed less than satisfactory [33]. Feng Qiankun surveyed college students' cognitive concern about national affairs from the perspective of political attention, depth, frequency and breadth [34]. Wu Xiaoyong and others compiled a questionnaire for college students' safety awareness. They considered that safety awareness is a kind of metacognitive ability, that is, the cognitive cognition of individuals [35]. He Liping and $\mathrm{Xu}$ Huicong conducted a survey of Hong Kong, Macao, and Taiwan university students studying in the Mainland from the perspective of identification. The results show that this group of people generally responds positively, but there are still a small number of people whose perceptions are not satisfactory [36]. Liu Yuqing's investigation and analysis of the national security cognition of college students in the network era found that there are defects in the form and content of national defense education in colleges and universities [37]. Scholars 'investigations from different perspectives have reflected that the level of contemporary college students' perception of national security is not ideal. This situation will undoubtedly pose a threat to China's national security. However, from a psychological perspective, which link is out of order? What kind of relationship is there... many questions have not yet been answered. There are still few studies on the combination of national security and psychology, and the use of statistical methods for structural and factor analysis needs more in-depth application. Only from the perspective of scientific psychological theories can we find the root cause of insufficient cognitive ability, and we can better put forward more symptomatic opinions for the next step of advancing the reform of national defense education and innovating new models of talent training in colleges and universities, thereby effectively improving contemporary national security awareness.

\section{Conclusion}

At present, China's development environment is very grim, and it has been tested in unprecedented ways in traditional security areas such as politics and military, as well as non-traditional areas such as economy and information. As the main force of national development and the successor of socialism, contemporary young people have always been the focus of rivalry between ourselves and the enemy. Therefore, the national security awareness of contemporary youth is related to the security of China's national development. At present, the theoretical basis of national security and psychological cognition has been relatively solid, but quantitative research has been slow. In the following research, combining literature analysis with field research, quantitative analysis and qualitative analysis, theoretical analysis and empirical analysis, and multi-dimensional, multi-angle, multi-disciplinary cross-cutting research on the issue of "national security awareness", there will be theoretical value and practical significance that cannot be underestimated.

\section{References}

[1] Liu Xuelin. The Formation of Japan's National Security Concept after the Cold War_— Based on Cognition and Value Judgment of "Threat" [J]. Northeast Asian Academic Journal, 2017 (01): $23-28$.

[2] Li Jiaheng. An Analysis of the Elements of National Security-On the Subtle Cognitive Differences between Scholars and Chairman Xi Jinping [J]. Journal of Sichuan Police College, 2015, 27 (02): 128-134.

[3] Xiao Ke. A Constructivist Analysis of National Security: An Ethical and Cultural Perspective [D]. Jilin University, 2005.

[4] Xu Dongbo. Summary of National Security Research Hotspots in the Past Decade — A Bibliometric Analysis Based on CNKI [J]. Journal of Jiangnan Social University, 2017, 19 (04): 34-40.

[5] Hu Hongbin. Research on China's National Security Issues: History, Evolution and Trends [J]. Journal of Renmin University of China, 2014, 28 (04): 148-155.

[6] Tian Qiubao. From False Perception to Security Dilemma: On National Cognition in International Anarchy [J]. Shang, 2016 (03): 62 .

[7] Han Zhiming, Shi Ruijie. Social recognition of national honor: an empirical analysis based on questionnaire data [J]. China Administration, 2015 (10): 64-68.

[8] Shi Haiming, Zeng Huafeng. National Cognitive Space Security Strategy from the Perspective of Science and Technology and War [J]. National Defense Science and Technology, 2014, 35 (03): 83-87. 
[9] Liu Peng. China's Political Cognition and the Evolution of National Imagery [J]. International Press, 2012, 34 (07): 26-31.

[10] Liu Danling. Manufacturing Consensus: Construction Strategy of "Imageization" of Chinese Image [J]. Zhongzhou Academic Journal, 2017 (10): 161-167.

[11] Liu Zhongquan. Analysis of Deng Xiaoping's National Cognitive Theory [J]. Journal of Wuhan University of Science and Technology (Social Science Edition), 2013, 15 (02): 161-166.

[12] Qu Jun. The Entanglement of Educational World and the Competitive World — A Basis of Readers' National Cognition in the Transformation Era [J]. Journal of East China Normal University (Philosophy and Social Sciences), 2014, 46 (04): 24- 25.

[13] Huang Dongsheng, Liu Wujun. Psychological process of internalization of the overall national security outlook of college students and its cultivation strategy [J]. Higher Education Forum, 2018 (07): 121-124.

[14] Wang Dan. Study on the influencing factors of coal mine workers' safety cognition [J]. Chinese Journal of Safety Science, 2011, 21 (12): 128-133.

[15] Ji Jixuan. Extending National Security to the Cognitive Domain [N]. China National Defense News, 2012-05-21 (004).

[16] Zeng Huafeng, Shi Haiming. On National Cognitive Space Security Strategy [J]. Theoretical Studies of Political Work in the Army, 2013, 14 (05): 130-138.

[17] Shen Yajun. Research on the Security of Cyberspace Cognitive Domain in China [J]. Southeast Communication, 2017 (07): 84-85.

[18] Meng Yue, Wang Sufang, Liu Jinjin, Cui Tengyao, Wei Feixiang, Yao Haowei. Investigation and analysis of fire safety awareness of college students based on psychology [J]. Science and Technology Bulletin, 2017, 33 (04).

[19] Zhang Min, Hao Subing, Gong Zijie, Zhang Yuxi. Measurement of College Students' Information Security Cognition and Its Relationship with Personality Characteristics $[\mathrm{J}]$. Research of Higher Engineering Education, 2016 (06): $144-148+174$

[20] Tian Zhidun. Research on College Students' Safety Cognitive Ability and Its Impact on Safety Behavior [D]. Beijing Jiaotong University, 2015.

[21] Yang Cun. Path Choice for College Students' Internal Safety Behavior Habits [J]. People's Forum, 2015 (02): 157-159.

[22] Yu Xiaofeng. "Identity Crisis" and National Security_Comment on Huntington's "Who Are We?" [J]. Mao Zedong and Deng Xiaoping Theoretical Research, 2006 (01): 44-54.

[23] Xie Guiping. Research on identification capacity building and border security governance [D]. Zhejiang University, 2015.
[24] Li Lerong, Weng Chuzheng. Multi-dimensional analysis of national identity of university students in the new era [J]. Legal Expo, 2019 (16): 58-60.

[25] Dong Hua, Ning Weining, Hou Guanhua. Cognitive Ability Measurement: Literature Review Based on Inclusive Design [J] Industrial Engineering and Management, 2016, 21 (05): 111-116.

[26] Kate E. Jacobs, John Roodenburg. The development and validation of the Self-Report Measure of Cognitive Abilities: A multitrait-multimethod study [J]. Intelligence, 2014, 42.

[27] Schmitter-Edgecombe Maureen, Parsey Carolyn, Cook Diane J. Cognitive correlates of functional performance in older adults: comparison of self-report, direct observation, and performance-based measures. $[\mathrm{J}]$. International Neuropsychological Society. Journal, 2011, 17 (5).

[28] La Fleur Claire G, Salthouse Timothy A. Which Aspects of Social Support Are Associated With Which Cognitive Abilities for Which People? [J]. The journals of gerontology. Series B, Psychological sciences and social sciences, 2017, 72 (6).

[29] Holland P W, Leinhardt S. Local structure in social networks [J]. Sociological methodology, 1976, 7: 1-45.

[30] Lydia Soh, Kate E. Jacobs. The biasing effect of personality on self-estimates of cognitive abilities in males and females [J]. Personality and Individual Differences, 2013, 55 (2).

[31] Yang Y W, Lim H S. A cognitive ability measuring system with cognitive loading task [M] // Future Information Technology. Springer, Berlin, Heidelberg, 2011: 325-328.

[32] Zsembik B A, Peek M K. Race differences in cognitive functioning among older adults $[\mathrm{J}]$. The Journals of Gerontology Series B: Psychological Sciences and Social Sciences, 2001, 56 (5).

[33] Jiang Liping. Investigation on the status quo of non-traditional security issues of contemporary college students [J]. Entrepreneurs World (Theoretical Edition), 2011 (03): $157-158$.

[34] Feng Qiankun. Discussion on College Students' Cognitive Concern about National Current Affairs [J]. Science \& Technology Economics Guide, 2016 (19): 147.

[35] Wu Xiaoyong, Gou Na, Li Yan. Development of safety awareness questionnaire for college students [J]. China Health Education, 2017, 33 (12).

[36] He Liping, Xu Huicong. The status quo, influencing factors and countermeasures of national identity of Hong Kong, Macao and Taiwan University students in Mainland universities under the new situation: Based on a survey and analysis of Xiamen University [J]. Higher Education Forum, 2018 (07): 106-110.

[37] Liu Yuqing. Data analysis of national security cognition of college students in the network age $[\mathrm{J}]$. Education and Teaching Research, 2018, 32 (12): 32-36 + 113. 